\title{
Decadal Oscillation of Fall Temperature in Taiwan
}

\author{
Jau-Ming Chen ${ }^{1, *}$, Fang-Chung $\mathrm{Lu}^{2}$, and Ching-Feng Shih ${ }^{3}$ \\ ${ }^{1}$ Center of General Studies and Institute of Navigation Science and Technology, National Kaohsiung Marine University, \\ Kaohsiung 805, Taiwan, ROC \\ ${ }^{2}$ Department of Computer Science and Information Engineering, Nan-Jeon Institute of Technology, Tainan 730, Taiwan, ROC \\ ${ }^{3}$ Research and Development Center, Central Weather Bureau, Taipei 100, Taiwan, ROC
}

Received 25 April 2007, accepted 21 September 2007

\begin{abstract}
This study verifies the existence of an evident decadal oscillation in fall (September - November) temperature for Taiwan. It has an island-wide spatial pattern and a central frequency of 11 years. A corresponding decadal-oscillation mode of tropical sea surface temperature (SST) is found to be largely responsible for inducing the decadal temperature oscillation for Taiwan via the following regulating processes. On a decadal timescale, periods of decadal warming in Taiwan concur with major cold anomalies in tropical SST over the eastern Indian Ocean and the central Pacific. These cold SST anomalies modulate tropical Walker circulation so as to produce anomalous descending centers in their regions. Meanwhile, the complementary anomalous ascending motion and anomalous low-level convergence center occur near the Maritime continent. These anomalous ascending and descending centers act as tropical forcing sources to evoke a low-level Rossby-wave-like circulation anomaly in the Asian-Pacific regions. Taiwan is surrounded by a low-level anomalous high to its east and an anomalous low to its west. These circulations induce anomalous flows from the south to warm Taiwan via anomalous warm advection. The above regulating processes reverse in polarity during periods of decadal cooling in Taiwan.
\end{abstract}

Key words: Decadal oscillation, Fall temperature, Taiwan, Warm advection, SST

Citation: Chen, J. M., F. C. Lu, and C. F. Shih, 2008: Decadal oscillation of fall temperature in Taiwan. Terr. Atmos. Ocean. Sci., 19, 497-504, doi. 10.3319/TAO.2008.19.5.497(A)

\section{INTRODUCTION}

Taiwan is a subtropical island in the western North Pacific (WNP). One marked climate feature in this region is the prominent variability of the large-scale monsoon-El Niño/Southern Oscillation (ENSO) system (e.g., Li and Yanai 1996; Zhang et al. 1997a; Chang et al. 2000a, b; Chou et al. 2003; Lau et al. 2004). Climate in Taiwan is affected by this large-scale system to exhibit interannual variability, such as in rainfall during spring (e.g., Jiang et al. 2003), the Mei-yu season (e.g., Chen 1994; Lu 1998), and summer (e.g., Chen et al. 2005).

On a longer timescale, rainfall in Taiwan was found to have evident decadal variability. Hung et al. (2004) demonstrated that spring rainfall in northern Taiwan can be regulated by circulation anomalies associated with the Pacific Decadal Oscillation (PDO, Mantua et al. 1997) to exhibit de-

\footnotetext{
* Corresponding author

E-mail: cjming@mail.nkmu.edu.tw
}

cadal variability. The positive (negative) PDO phase in spring causes an anomalous low-level high (low) over the Philippine Sea (southeast of Taiwan), which enhances (suppresses) moisture transport into Taiwan via anomalous southwesterly (northeasterly) winds to result in more (less) spring rainfall in northern Taiwan. In fall, a quasi-20-year oscillation in rainfall was found to be most significant in eastern Taiwan in connection with the variability of the overlying low-level circulation (Chen and Wang 2000a). In its positive (negative) phase, an anomalous low (high) over the Philippine Sea sets favorable (unfavorable) conditions for tropical cyclone (TC) formation. TCs formed in this region are later steered (hindered) by the anomalous low (high) to move toward Taiwan, leading to increasing (decreasing) TC-induced rainfall on the windward (east) side. Fall rainfall in Taiwan thus varies with TC activities to exhibit an apparent decadal oscillation in eastern Taiwan.

Surface temperature in Taiwan also exhibits noticeable decadal variability. A warming trend appears in all seasons, 
with a minimum of $0.6^{\circ} \mathrm{C} 100 \mathrm{yrs}^{-1}$ in winter and a maximum of $1.6^{\circ} \mathrm{C} 100 \mathrm{yrs}^{-1}$ in summer (e.g., Chen and Wang 2000b; Hsu and Chen 2002). This trend is compatible with the averaged trend of nearly 2000 stations over the Northern Hemisphere (NH) in winter, but about three times larger in summer (e.g., Jones 1994). Analyses show that the warming trend in Taiwan is closely connected to the long-term warming of SST in the South China Sea and the northwestern Pacific (e.g., Chen and Wang 2000b). The above studies disclose that the decadal-variability phenomena in Taiwan are in response to large-scale regulating processes associated with background changes in the ocean-atmosphere.

Besides the warming trend, Chen and Wang (2000b) analyzed the time series of fall temperature in Taiwan and suggested the possible existence of a quasi-10-year oscillation. As discussed above, such a decadal oscillation could be a response to large-scale background variability. Nevertheless, this decadal phenomenon and its accompanying regulating mechanisms have not been systematically verified. This study intends to extend the work of Chen and Wang (2000b) and aims at investigating the decadal-oscillation feature of fall temperature in Taiwan. Major objectives of this study are as follows:

- To verify the existence of a decadal oscillation in fall temperature for Taiwan.

- To delineate the characterizing spatiotemporal features of this decadal oscillation and to discuss its relationship in the context of a warming trend.

- To identify associated regulating processes imposed by large-scale ocean-atmosphere.

- To search the corresponding large-scale decadal-oscillation mode in the atmosphere or ocean, if such a mode exists.

Analysis results of this study should justify the existence of a decadal oscillation of fall temperature in Taiwan. They should also help to advance our knowledge with respect to the dynamics of decadal climate variability in Taiwan and the surrounding Asian regions.

\section{DATA}

Three datasets are analyzed in this study. The first dataset includes surface air temperature records from 14 meteorological stations in Taiwan (Fig. 1). These data are used to depict the decadal features of fall temperature in Taiwan. The second dataset includes upper-air winds of the National Centers for Environmental Prediction-National Center for Atmospheric Research (NCEP-NCAR) reanalysis data (Kalnay et al. 1996). The third dataset is the extended reconstructed SST generated by Smith and Reynolds (2003, 2004). The reanalysis and SST datasets are used to examine regulating processes imposed by large-scale ocean-atmosphere on decadal variability in Taiwan. All datasets span from 1948 to 2002 and their fall (September - November)averaged fields are analyzed in this study.

\section{DECADAL VARIABILITY OF FALL TEMPERATURE IN TAIWAN}

Decadal temperature variability in Taiwan seems to consist of two components: a warming trend and decadal oscillation. The warming trend in the $\mathrm{NH}$ was considered to be partially attributable to the urbanization effect; the effect of which is particularly strong in cities with a population of more than 100 thousand (e.g., Kukla et al. 1986; Karl et al. 1988; Wood 1988). Since Taiwan is a highly populated area, possible impacts of the urbanization effect need to be taken into account in analyses for the decadal temperature variability. The 14 meteorological stations in Taiwan in Fig. 1 are separated into urban and suburban stations based upon whether the located city has a population of more than 100 thousand. This separation concludes eight urban stations and six suburban stations. Table 1 lists detailed information for these stations. The 1948 - 2002 time series (histogram) of fall temperatures averaged from these two station groups are shown in Fig. 2. Seven-year-running means of the time series are superimposed to depict the decadal variability features (dashed curve). Power spectral analyses of these time series are computed to detect their decadal-oscillation modes. The running means manifest that both the urban and suburban temperature time series exhibit a relatively clear

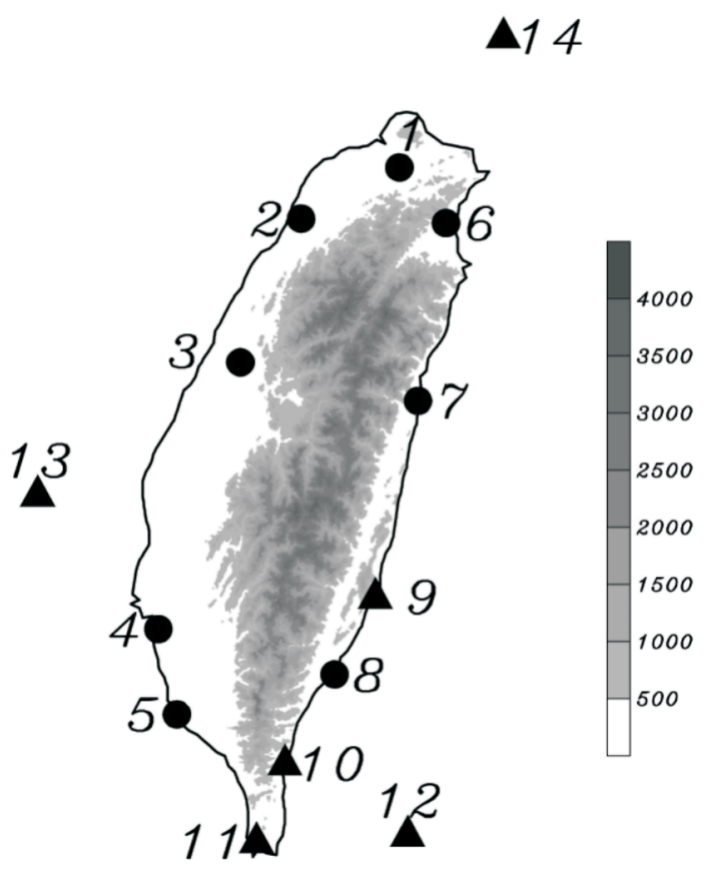

Fig. 1. Geographical distributions of 14 meteorological stations in Taiwan, eight in urban regions (marked by ) and six in suburban regions (marked by $\mathbf{\Delta}$ ). Detailed information of these stations is listed in Table 1. 
Table 1. The population and warming trend of eight urban and six suburban meteorological stations in Taiwan. Unit for population is thousand, and ${ }^{\circ} \mathrm{C} 100 \mathrm{yrs}^{-1}$ for trend.

\begin{tabular}{cccccc}
\hline & No & Station & Population & Warming trend & Trend mean \\
\hline \multirow{6}{*}{ Urban } & 1 & Taipei & $2630 \mathrm{~K}$ & 1.8 & \\
& 2 & Hsinchu & $390 \mathrm{~K}$ & 0.9 & \\
& 3 & Taichung & $1044 \mathrm{~K}$ & 1.7 & \\
& 4 & Tainan & $760 \mathrm{~K}$ & 1.2 & \\
& 5 & Kaohsiung & $1515 \mathrm{~K}$ & 2.2 & \\
& 6 & Ilan & $95 \mathrm{~K}$ & 1.3 & \\
& 7 & Hualien & $110 \mathrm{~K}$ & 1.3 & \\
\multirow{3}{*}{ Suburban } & 8 & Taitung & $111 \mathrm{~K}$ & 1.5 & \\
& 8 & Chengkung & $17 \mathrm{~K}$ & 0.8 & \\
& 9 & Tawu & $7 \mathrm{~K}$ & 0.3 & \\
& 10 & Hengchun & $31 \mathrm{~K}$ & 0.1 & \\
& 11 & Lanyu & $4 \mathrm{~K}$ & 0.6 & \\
& 12 & Penghu & $53 \mathrm{~K}$ & 0.5 & \\
& 13 & Pengchiayu & $0.5 \mathrm{~K}$ & 0.4 & \\
\hline
\end{tabular}

(a) T (Urban)

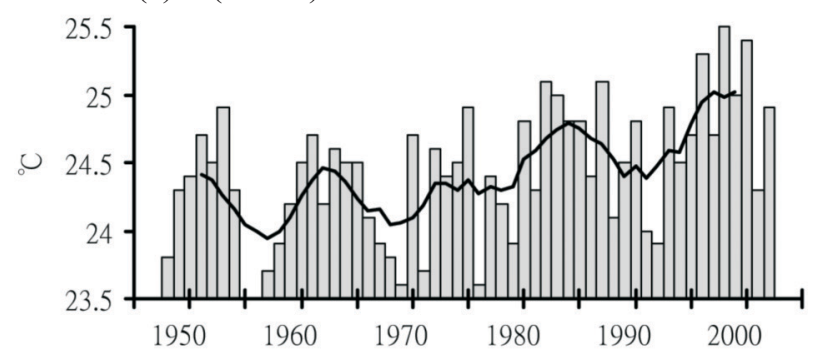

(b) $\mathrm{T}$ (Suburban)

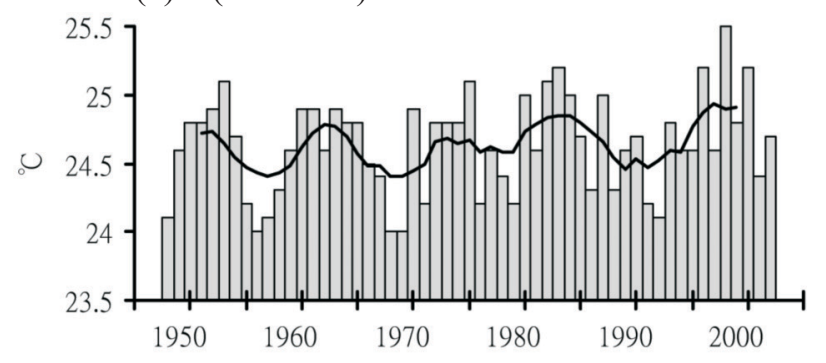

(c) T (Urban)

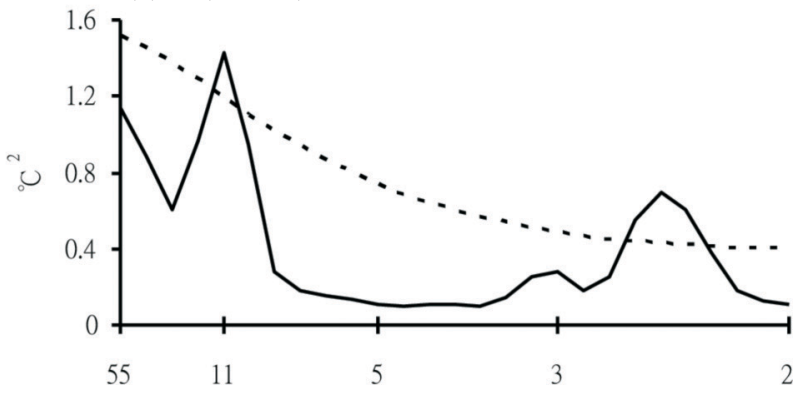

(d) T (Suburban)

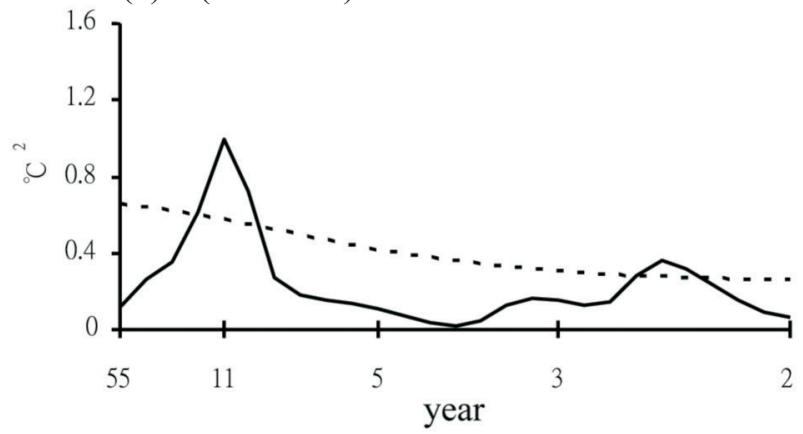

Fig. 2. The 1948 - 2002 time series of fall temperatures averaged from (a) eight urban and (b) six suburban stations in Taiwan and the power spectral analysis of temperature time series for the (c) urban and (d) suburban stations. Solid curves superimposed in (a) and (b) are the seven-year-running means of temperature. Dashed curves shown in (c) and (d) represent the $10 \%$ significance level.

and coherent oscillating feature, with maximum phases in the early 1950s, early 1960s, early 1970s, mid 1980s, and late 1990s. A warming trend is embedded in the running means, which is more evident in the urban stations than in the suburban stations. Power spectral analysis and its 10\% significance level (dashed line) disclose two significant oscillation modes: 11 years and 2 - 3 years. This suggests the existence of a near-11-year decadal-oscillation mode in Taiwan's fall temperature. This near-11-year mode is also significant at the $5 \%$ level for the suburban stations, but slightly 
below the $5 \%$ level for the urban stations. It also shows that the warming trend (55-year mode) is larger in the urban stations than in the suburban stations, consistent with the feature revealed by the running mean time series.

The warming trend and oscillating feature for the urban and suburban stations are compared quantitatively. The trend in fall temperature at each station is estimated by least-square-fit and illustrated in Table 1. The oscillating feature is depicted by the detrended seven-year-running mean, which is hereafter referred to as the decadal-oscillation component. The trend and decadal-oscillation components of temperature anomaly time series for urban and suburban stations are displayed in Fig. 3. Overall, the urban stations have a larger long-term trend than the suburban regions (Fig. 3a). The warming trend in the urban stations ranges from 0.9 to $2.2^{\circ} \mathrm{C} 100 \mathrm{yr}^{-1}$ with an average of

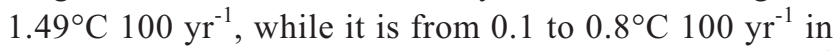
the suburban stations with an average of $0.45^{\circ} \mathrm{C} 100 \mathrm{yr}^{-1}$ (see Table 1). The greatest trend occurs in the two largest cities, Taipei and Kaohsiung. For the decadal oscillation, the detrended time series (Fig. 3b) show a relatively coherent oscillation between the urban and suburban regions. These two time series have a 0.97 correlation coefficient and a comparable standard deviation of about $0.15^{\circ} \mathrm{C}$. The above analyses manifest that urbanization effect is an important contributor to the evident warming trend in Taiwan, resulting in a near three-time warming in populated cities than in

\section{(a) $\mathrm{T}$ (Trend)}

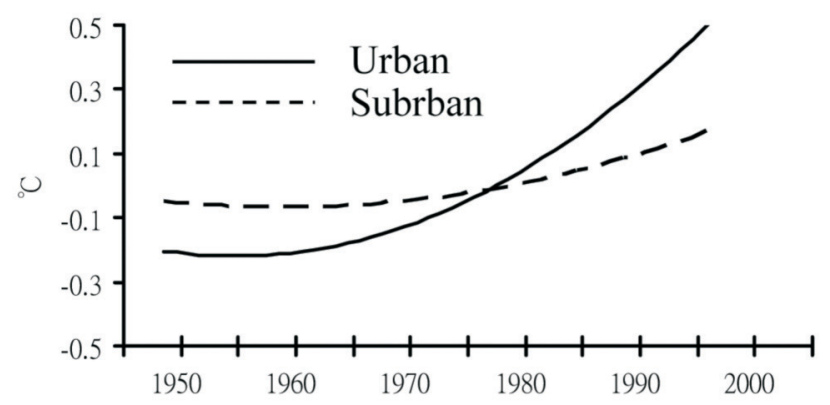

(b) $\mathrm{T}$ (Oscillation)

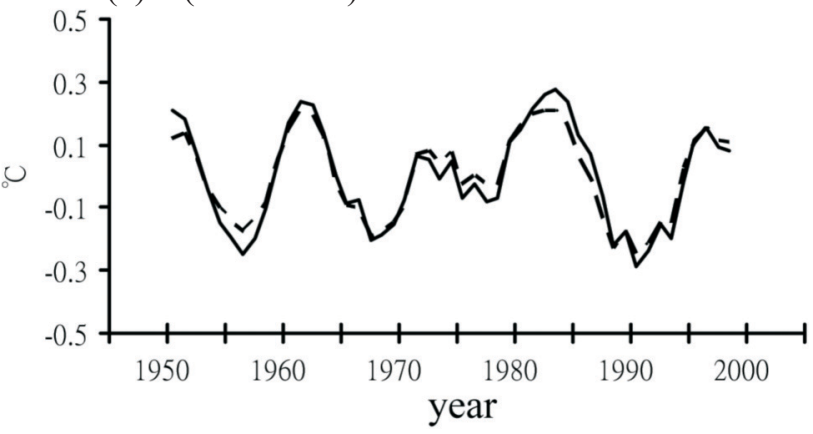

Fig. 3. The (a) warming trend and (b) decadal-oscillation component (represented by the detrended seven-year-running mean) of fall temperatures averaged from the urban and suburban stations in Taiwan. rural towns during the past 50 years. One thus may regard prominent warming in Taiwan in the last century to be jointly caused by global warming and local urbanization effect. It also demonstrates the occurrence of a decadal oscillation in fall temperature for Taiwan, which is irrelevant to global warming and urbanization effect. Further analyses indicate that this decadal temperature oscillation is only apparent in the period after the late 1940s, but becomes indiscernible in the period before (not shown). Its detailed characteristics and possible causes are of interest to examine.

The spatiotemporal characteristics of the decadal temperature oscillation can be delineated by empirical orthogonal function (EOF) analysis. The decadal-oscillation components of fall temperature from Taiwan's 14 stations are subject to this analysis. The first eigenmode accounts for $71 \%$ of the total temperature variance from these stations. Its principal components (Fig. 4a) vary coherently with the detrended temperature time series of Taiwan in Fig. 3b, as disclosed by their 0.99 correlation coefficient. The first eigenvector (Fig. 4b) shows a uniform sign and relatively comparable amplitudes $(0.16 \sim 0.35)$ for temperature anomalies over the entire island. The first eigenmode is representative of the decadal-oscillation mode of fall temperature in Taiwan. It indicates that this oscillation is an island-wide phenomenon. In fact, decadal time series of fall temperature

(a) $\mathrm{C} 1(\mathrm{~T})$

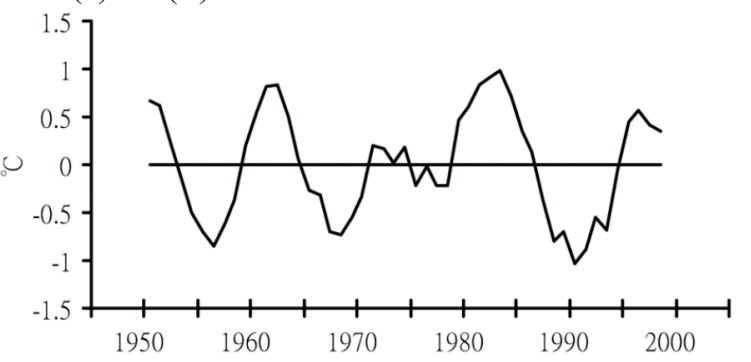

(b) E1 (T)

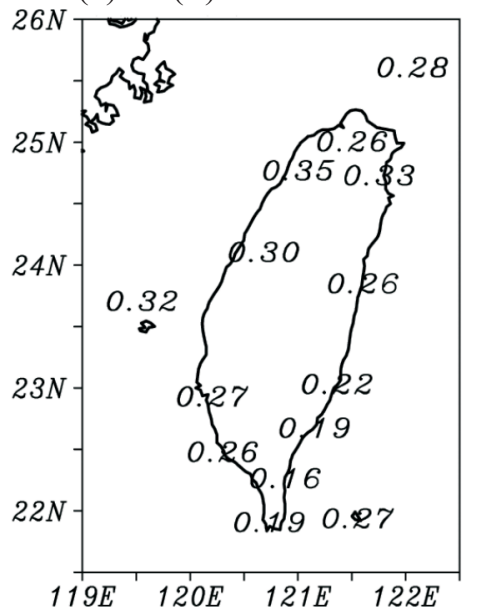

Fig. 4. The (a) principal component and (b) eigenvector of the first eigenmode for fall temperature of the 14 stations in Taiwan. 
at the 14 Taiwan stations all exhibit an evident decadal oscillation (not shown). Island-wide climate features of Taiwan are generally in close relation to the large-scale background variations (e.g., Hsu and Chen 2002; Chen et al. 2005), in particular to the low-level circulation anomalies (e.g., Chen 1994; Jiang et al. 2003; Hung et al. 2004). The possible regulating processes for this decadal oscillation are thus searched from the large-scale anomalies of ocean and the low-level atmosphere.

\section{THE LARGE-SCALE REGULATING PROCESSES}

The large-scale regulating processes for the decadal temperature oscillation in Taiwan are interpreted from composite difference patterns of background fields between maximum and minimum phases (maximum minus minimum). As indicated by the principal components in Fig. 4a, the major maximum phases are in 1951, 1963, 1984, and 1997, while the major minimum phases are in 1957, 1969, and 1991. Each maximum or minimum phase is expressed by a composite anomaly averaged from three years. For example, the anomaly mean of $1996-1998$ is used to present the 1997 maximum phase. The composite difference patterns of the decadal-oscillation component of $850-\mathrm{mb}$ streamfunction $(S 850)$ are investigated in Fig. 5a. Its salient feature is a Rossby-wave-like pattern with a meridional pair of anomalous lows over the Asian-Indian Ocean regions and a meridional pair of anomalous highs over the western Pacific. Taiwan is sandwiched by an anomalous low to the west and an anomalous high to the east. These circulation anomalies induce anomalous southwesterly and southeasterly winds to bring warm air from the south into Taiwan, as revealed by the accompanying 10-m wind anomalies in Fig. 5b. These anomalous flows from the south cause anomalous warm advection to warm Taiwan. As such, Taiwan is in a warming phase.

The tropical forcing anomaly responsible for this Rossby-wave-like pattern may be interpreted from the composite difference patterns of 850 -mb velocity potential ( $X 850$, Fig. 5c). The $X 850$ anomalies characterize a major convergence center around the Maritime continent. This center, according to the theory of Matsuno (1966) and Gill (1980), is one of the major tropical forcing anomalies for prompting the two meridional pairs of circulation anomalies over the Asian-western Pacific regions in S850. Does this convergence anomaly primarily originate from local or remote effects? To answer this question, the tropical Walker circulation anomaly is examined. Walker circulation is generally expressed in terms of a vertically-integrated mass flux function $\Psi_{m}=\int_{p_{1}}^{p_{0}} u_{d} d p$ (Newell et al. 1974), where $p_{1}=100 \mathrm{mb}, p_{0}=1000 \mathrm{mb}, u_{d}$ is the zonal divergent wind, and $p$ is the pressure. The composite difference pattern of $\Psi_{m}$ anomaly across the Equator (Fig. 5d) is noted by a positive (counterclockwise) cell to the west of the anomalous $X 850$ convergence center (near $120^{\circ} \mathrm{E}$ ), and a negative (clockwise) cell to the east. These two cells reflect a strong anomalous upward motion over the anomalous convergence center around the Maritime continent. This upward motion is accompanied by major downward motions over the equatorial eastern Indian Ocean (about $90^{\circ}-80^{\circ} \mathrm{E}$ ) and the equatorial central Pacific (about $170^{\circ}-180^{\circ} \mathrm{E}$ ).

Tropical Walker circulation anomaly is mainly modulated by underlying SST variability (e.g., Wang 1992; Oort and Yienger 1996; Chen and Lu 2000). The corresponding

(a) $S 850$
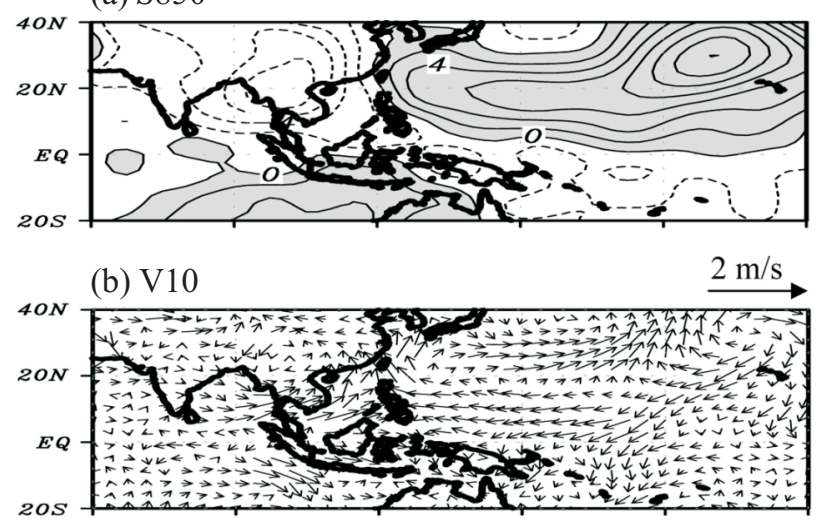

(c) $X 850$

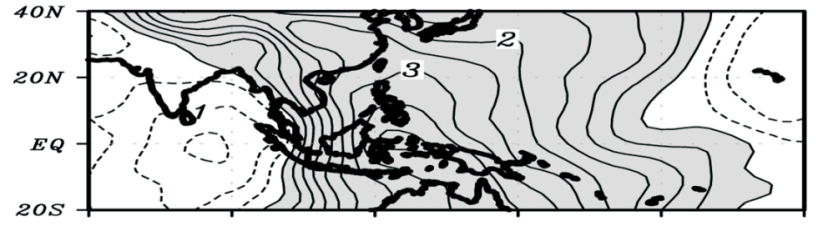

(d) $\Psi_{\mathrm{m}}$

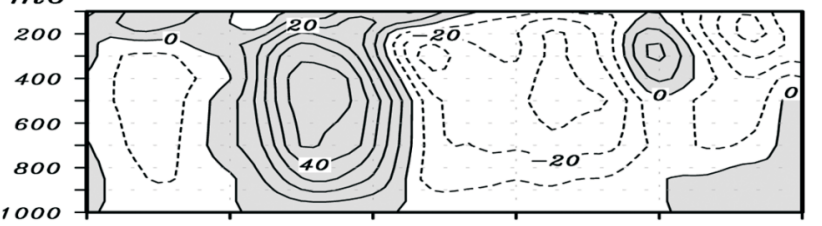

(e) SST

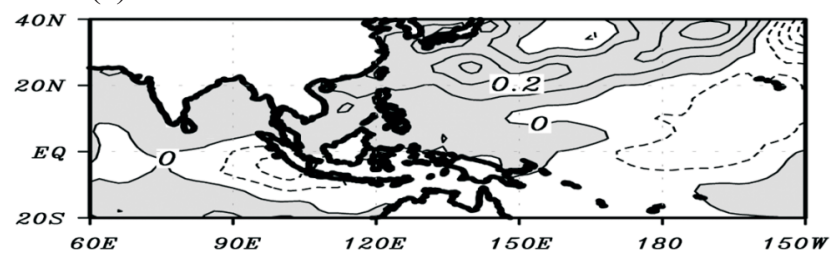

Fig. 5. Composite difference patterns of decadal-oscillation component between maximum and minimum phases (maximum minus minimum) of the decadal oscillation of Taiwan's fall temperature: (a) 850-mb streamfunction, (b) $10-\mathrm{m}$ wind, (c) 850 -mb velocity potential, (d) tropical Walker circulation across the Equator, and (e) sea surface temperature. Contour intervals: (a) $2 \times 10^{5} \mathrm{~m}^{2} \mathrm{~s}^{-1}$, (c) $0.5 \times$ $10^{5} \mathrm{~m}^{2} \mathrm{~s}^{-1}$, (d) $10 \mathrm{~m} \mathrm{~s}^{-1} \mathrm{mb}$, and (e) $0.1^{\circ} \mathrm{C}$. Positives anomalies are shaded. 
composite difference pattern of SST (Fig. 5e) displays major negative anomalies in the tropics, but major positive anomalies in the northwestern Pacific. Equatorial cooling is particularly evident over the eastern Indian Ocean and the central Pacific near the Date line, which are spatially coherent with the major downward motion branches of $\Psi_{m}$ anomalies in Fig. 5d. On the other hand, no major positive SST anomaly appears near the Maritime continent to link with the upward motion and convergence anomalies over there. These results suggest that the appearance of a major convergence anomaly over the Maritime continent is likely connected to remote SST anomalies over the eastern Indian Ocean and the central Pacific via the atmospheric bridge effect (e.g., Klein et al. 1999), instead of to local SST anomalies.

In Fig. 5e, warm SST anomalies appear over the South China Sea and the East China Sea, where evident anomalous flows from the south (Fig. 5b) induced by the low-level Rossby-wave-like circulation pattern (Fig. 5a) coexist. This wind-SST relationship indicates that anomalous flows from the south cause warm advection to warm these regions, including Taiwan. It also suggests that decadal SST variability in the South China Sea-East China Sea regions results in part from atmospheric forcing. The important role of atmospheric forcing to SST variability in these regions also occurs on the interannual (e.g., Kitoh et al. 1999; Wang et al. 2004) and seasonal (e.g., Qu 2001; Chen et al. 2003) timescales. It is interpreted that decadal warming in Taiwan and its surrounding oceans may be a response to atmospheric forcing induced by major cold SST anomalies in the tropical central Pacific and the tropical eastern Indian Ocean. In other words, there may be a decadal-oscillation mode in tropical SSTs to act as the center of actions for evoking the decadal oscillation of fall temperature in Taiwan. To verify this interference, the decadal oscillation of tropical SST is analyzed below.

\section{DECADAL-OSCILLATION MODE OF TROPICAL SST}

The decadal-oscillation components of tropical SST from the Indian Ocean to the central Pacific Ocean $\left(60^{\circ} \mathrm{E}\right.$ $150^{\circ} \mathrm{W}, 20^{\circ} \mathrm{S}-20^{\circ} \mathrm{N}$ ) are subjected to EOF analysis to isolate its major oscillation modes. The first five eigenmodes account for $54 \%, 26 \%, 6 \%, 5 \%$, and $3 \%$ of total variance of these tropical SST anomalies. The correlation coefficients of principal components between the first five SST eigenmodes and the first eigenmode of Taiwan's fall temperature (see Fig. 4a) are $-0.11,0.23,0.71,-0.20$, and 0.15 . The third SST eigenmode appears as the one with a close temporal phase to the decadal oscillation of fall temperature in Taiwan. The principal component and eigenvector of the third SST mode are shown in Fig. 6. Its temporal evolution (dashed curve, Fig. 6a) characterizes a clear decadal oscillation. It tends to be coherent with the oscillation of Taiwan's fall temperature (solid curve), except for a phase lag in the cycle between the late 1970s and the early 1980s. The eigenvector (Fig. 6b) features major cold anomalies in the tropical eastern Indian Ocean and the tropical central Pacific, and warm anomalies in the South China Sea. These patterns resemble well the composite difference patterns of SST anomalies in Fig. 5e. The EOF analysis clearly demonstrates the existence of a decadal-oscillation mode in tropical SST, which has a close connection with decadal temperature variability in Taiwan. This SST mode is not significant among all SST modes. However, it does affect the decadal variability of atmospheric circulation, which just happens to exert the greatest influence on surface temperature in the South China SeaTaiwan-East China Sea regions via its accompanying anomalous flows and thermal advection. Subsequently, the signature of this decadal SST mode is transferred to fall temperature in Taiwan so that it undergoes a decadal oscillation.

\section{CONCLUDING REMARKS}

Previous research has hinted that a decadal oscillation may exist in fall (September - November) temperature for Taiwan. The main purpose of this study is to comprehensively examine this oscillation phenomenon, focusing on its general characteristics and the associated regulating processes imposed by large-scale ocean-atmosphere. Analysis results show that the decadal oscillation of fall temperature in Taiwan is an island-wide phenomenon, with an oscillating frequency around 11 years. A corresponding decadal-oscillation mode exists in tropical SST. This SST mode effectively regulates the oscillation of Taiwan's fall temperature via the variability of atmospheric circulation. Key elements involved in these decadal regulating processes are illustrated

(a) $\mathrm{C} 3(\mathrm{SST})$

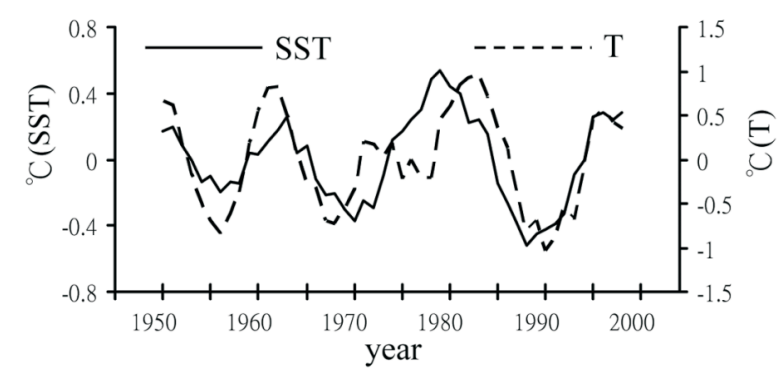

(b) E3 (SST)

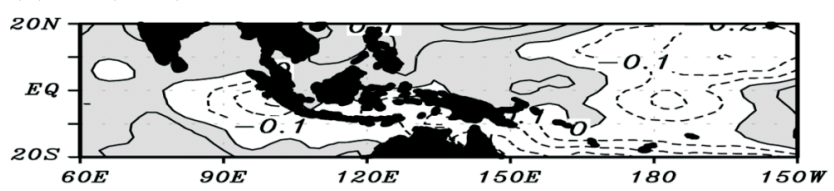

Fig. 6. The (a) principal component and (b) eigenvector of the third eigenmode for decadal-oscillation component of tropical SST. The first principal component of Taiwan's fall temperature is shown in (a) to compare with the decadal-oscillation phase of this SST mode. Contour intervals in (b) are 0.1 and positive anomalies are shaded. 
by the schematic diagram in Fig. 7. For periods of decadal warming in Taiwan, major tropical SST appears as cold anomalies over the eastern Indian Ocean and the central Pacific. These cold SST anomalies directly modulate tropical Walker circulation to form anomalous subsidence in their regions, while a complementary ascending branch forms in the tropical western Pacific. The ascending anomaly is accompanied by a major low-level convergence anomaly. The above anomalous ascending and descending centers act as topical forcing anomalies to excite the atmosphere, resulting in low-level Rossby-wave-like circulation patterns over the Asia-western Pacific regions. Taiwan is sandwiched by an anomalous high and low to its east and west, respectively. These circulation anomalies induce anomalous southeasterly and southwesterly winds onto Taiwan. These anomalous flows are warm in nature and cause warm advection to provide heat for Taiwan, leading to a warming phase. These regulating processes reverse polarity in the periods of decadal cooling. It is concluded that fall temperature in Taiwan is under the systematic influence of a decadal-oscillation mode of tropical SST and its associated large-scale atmospheric circulation anomalies to produce an apparent decadal oscillation.

This study verifies the existence of a significant decadal oscillation of fall temperature in Taiwan. It also uncovers the existence of a decadal-oscillation mode in tropical SST. Although this mode is not significant, its impacts just reach their maximum strength in regions across the South China Sea, Taiwan, and the East China Sea. As such, its decadal signal is thus apparently embedded in the fall temperature of Taiwan. This decadal tropical SST mode bears some features resembling the decadal mode of El Niño Modoki found by Weng et al. (2007). Temporally, both modes have a major decadal-oscillation frequency around $10-15$ years. Spatially, both modes feature a tripole structure in the tropical SST anomalies, which is accompanied by an anomalous two-cell Walker circulation. These decadal SST modes exert impacts on the Asian-Pacific climate via anomalous atmospheric circulations forced directly or indirectly by their anomalous tropical SST zonal gradients.

On the other hand, the decadal SST mode found in this study seems to be different in many aspects from the most noticed decadal mode of the Pacific SST; i.e., the so-called Pacific Decadal Oscillation (PDO). The PDO is a basinscale phenomenon, characterizing an abrupt change toward a warmer tropical eastern Pacific and a colder extratropical central North Pacific in the late 1970s (e.g., Graham 1994; Trenberth and Hurrell 1994; Kachi and Nitta 1997; Zhang et al. 1997b; Schneider and Cornuelle 2005). The extratropical SST anomaly crosses the North Pacific poleward of $20^{\circ} \mathrm{N}$ with a center along $40^{\circ} \mathrm{N}$ (see Fig. 4 of Zhang et al. 1997b), and is stronger in strength than its tropical counterpart (e.g., Zhang et al. 1998). The decadal SST mode found in this study has its centers of action in the tropical eastern Indian

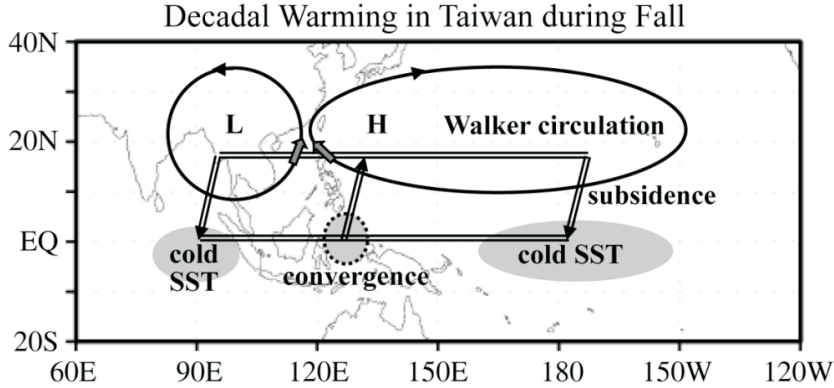

Fig. 7. A schematic diagram to illustrate the key elements involved in the decadal regulating processes imposed by large-scale ocean-atmosphere on the decadal oscillation of fall temperature in Taiwan. Here shows the case of decadal warming in Taiwan, while the decadal cooling case exhibits the opposite polarity.

Ocean and the tropical central Pacific. Its subtropical components seem to be a response to atmospheric circulation variability forced by tropical SST. Regarding temporal features, the major oscillating frequency of the PDO is around 20 - 30 years (e.g., Mantua et al. 1997; Newman et al. 2003), while the decadal SST mode in this study is around $10-15$ years. The above differences in spatial and temporal features suggest that the decadal SST mode found in this study behaves very differently from the PDO. Its robustness and detailed characteristics shall be of interest for future research.

Acknowledgements The authors thank Profs. Bin Wang and Tim Li for their discussions. This study was supported by the National Science Council, Taiwan, under NSC 952111-M-022-001-MY3.

\section{REFERENCES}

Chang, C. P., Y. Zhong, and T. Li, 2000a: Interannual and interdecadal variations of the East Asian summer monsoon and tropical Pacific SSTs. Part II: Roles of subtropical ridge. J. Climate, 13, 4310-4325.

Chang, C. P., Y. Zhong, and T. Li, 2000b: Interannual and interdecadal variations of the East Asian summer monsoon and tropical Pacific SSTs. Part II: Meridional structure of the monsoon. J. Climate, 13, 4326-4340.

Chen, G. T. J., 1994: Large-scale circulation associated with the East Asian summer monsoon and the Mei-Yu over South China and Taiwan. J. Meteor. Soc. Japan, 72, 959-983.

Chen, J. M. and M. M. Lu, 2000: Interannual variation of the Asian-Pacific atmospheric system in association with the northern summer SST changes. Terr. Atmos. Ocean. Sci., 11, 833-860.

Chen, J. M. and F. J. Wang, 2000a: The long-term variability of rainfall of Taiwan: The quasi-20-year oscillation of autumn rainfall. Atmos. Sci., 28, 343-361. (in Chinese)

Chen, J. M. and F. J. Wang, 2000b: The long-term warming in Taiwan and its relationship to the Pacific SST variability. Atmos. Sci., 28, 221-242. (in Chinese) 
Chen, J. M., C. P. Chang, and T. Li, 2003: Annual cycle of the South China Sea surface temperature using the NCEP/ NCAR reanalysis. J. Meteor. Soc. Japan, 81, 879-884.

Chen, J. M., F. C. Lu, S. L. Kuo, and C. F. Shih, 2005: Summer climate variability in Taiwan and associated large-scale processes. J. Meteor. Soc. Japan, 89, 499-516.

Chou, C., J. Y. Tu, and J. Y. Yu, 2003: Interannual variability of the western North Pacific summer monsoon: Differences between ENSO and non-ENSO years. J. Climate, 16, 2275-2287.

Gill, A. E., 1980: Some simple resolutions for heat-induced tropical circulation. Quart. J. Roy. Meteor. Soc., 106, 447-462.

Graham, N. E., 1994: Decadal-scale climate variability in the tropical and North Pacific during the 1970s and 1980s: Observations and model results. Climate Dyn., 10, 135-162.

Hsu, H. H. and C. T. Chen, 2002: Observed and projected climate change in Taiwan. Meteor. Atmos. Phys., 79, 87-104.

Hung, C. W., H. H. Hsu, and M. M. Lu, 2004: Decadal oscillation of spring rain in northern Taiwan. Geophys. Res. Lett., 31, L22206, doi: 10.1029/2004GL021344.

Jiang, Z., G. T. J. Chen, and N. C. Wu, 2003: Large-scale circulation patterns associated with heavy spring rain events over Taiwan in strong ENSO and non-ENSO years. Mon. Wea. Rev., 131, 1769-1782.

Jones, P. D., 1994: Hemispheric surface air temperature variations: A reanalysis and an update to 1993. J. Climate, 11, 1794-1802.

Kachi, M. and T. Nitta, 1997: Decadal variations of the global atmospheric-ocean system. J. Meteor. Soc. Japan, 75, 657-675.

Kalnay, E., M. Kanamitsu, R. Kistler, W. Collins, D. Deaven, L. Gandin, M. Iredell, S. Saha, G. White, J. Woollen, Y. Zhu, A. Leetmaa, R. Reynolds, M. Chelliah, W. Ebisuzaki, W. Higgins, J. Janowiak, K. C. Mo, C. Ropelewski, J. Wang, Roy Jenne, and Dennis Joseph, 1996: The NCEP/NCAR 40-year Reanalysis Project. Bull. Amer. Meteor. Soc., 77, 437-471.

Karl, T. R., H. F. Diaz, and G. Kukla, 1988: Urbanization: Its detection and effect in the United States climate records. J. Climate, 1, 1099-1123.

Kitoh, A., T. Motoi, and H. Koide, 1999: SST variability and its mechanism in a coupled atmosphere-mixed layer ocean model. J. Climate, 12, 1221-1239.

Klein, S. A., B. J. Soden, and N. C. Lau, 1999: Remote sea surface temperature variations during ENSO: Evidence for a tropical atmospheric bridge. J. Climate, 12, 917-932.

Kukla, G., J. Gavin, and T. R. Karl, 1986: Urban warming. J. Climate Appl. Meteor., 25, 1265-1270.

Lau, W. K. M., K. M. Kim, and J. Y. Lee, 2004: Interannual variability, global teleconnection, and potential predictability associated with the Asian summer monsoon. In: Chang, C. P. (Ed.), East Asian Monsoon, World Scientific Series on Meteorology and East Asia, Vol. 2, World Scientific, 153-172.

Li, C. and M. Yanai, 1996: The onset and interannual variability of the Asian summer monsoon in related to land-sea ther- mal contrast. J. Climate, 9, 358-375.

Lu, M. M., 1998: A study on the relationship of the onset dates of the South China Sea summer monsoon and Taiwan precipitation in the Mei-Yu season. Atmos. Sci., 26, 205-226. (in Chinese)

Mantua, N. J., S. R. Hare, Y. Zhang, J. M. Wallace, and R. C. Francis, 1997: A Pacific interdecadal climate oscillation with impacts on salmon production. Bull. Amer. Meteor. Soc., 78, 1069-1079.

Matsuno, T., 1966: Quasi-geostrophic motions in equatorial areas. J. Meteor. Soc. Japan, 2, 25-43.

Newell, R. E., J. W. Kidson, D. J. Vincent, and G. J. Boer, 1974: The general circulation of the tropical atmosphere. MIT Press, $370 \mathrm{pp}$.

Newman, M., G. P. Compo, and M. A. Alexander, 2003: ENSO-forced variability of the Pacific decadal oscillation. J. Climate, 16, 3853-3857.

Oort, A. H. and J. J. Yienger, 1996: Observed long-term variability in the Hadley and Walker circulation and its connection to ENSO. J. Climate, 9, 2751-2767.

Qu, T., 2001: Role of ocean dynamics in determining the mean seasonal cycle of the South China Sea surface temperature. J. Geophys. Res., 106-C4, 6943-6955.

Schneider, N. and B. D. Cornuelle, 2005: The forcing of the Pacific decadal oscillation. J. Climate, 18, 4355-4373.

Smith, T. M. and R. W. Reynolds, 2003: Extended reconstruction of global sea surface temperature based on COADS data (1854-1997). J. Climate, 16, 1495-1510.

Smith, T. M. and R. W. Reynolds, 2004: Improved extended reconstruction of SST (1854-1997). J. Climate, 17, 2466-2477.

Trenberth, K. E. and J. W. Hurrell, 1994: Decadal atmosphereocean variations in the Pacific. Climate Dyn., 9, 303-319.

Wang, B., 1992: The vertical structure and development of the ENSO anomaly mode during 1979-1989. J. Atmos. Sci., 49, 698-712.

Wang, B., I. S. Kang, J. Y. Lee, 2004: Ensemble Simulations of Asian-Australian Monsoon Variability by 11 AGCMs. $J$. Climate, 17, 803-818.

Weng, H., K. Ashok, S. K. Behera, S. A. Rao, and T. Yamagata, 2007: Impacts of recent El Niño Modoki on dry/wet conditions in the Pacific rim during boreal summer. Climate Dyn., doi: 10.1007/s00382-007-0234-0.

Wood, F. B., 1988: Comment: On the need for validation of the Jones et al. Temperature trends with respect to urban warming. Clim. Change, 12, 297-312.

Zhang, Y., K. R. Sperber, and J. S. Boyle, 1997a: Climatology and interannual variation of the East Asian winter monsoon: Results from the 1979-95 NCEP/NCAR reanalysis. Mon. Wea. Rev., 125, 2605-2619.

Zhang, Y., J. Wallace, and D. Battisti, 1997b: ENSO-like interdecadal variabilily: 1900 - 1993. J. Climate, 10, 10041020.

Zhang, Y., J. R. Norris, and J. M. Wallace, 1998: Seasonally of large-scale atmosphere-ocean interaction over the North Pacific. J. Climate, 11, 2473-2481. 